\title{
Mogami Tokunai's wood collection from Hokkaido, Japan: an early record of Ainu wood culture
}

\author{
Pieter Baas $^{1, *}$, Tomoyuki Fujii ${ }^{2}$, Nobushige Kato ${ }^{3}$, Mechtild Mertz $^{4}$, Shuichi Noshiro ${ }^{5}$, and Gerard Thijsse ${ }^{6}$ \\ ${ }^{1}$ Naturalis Biodiversity Center and Leiden University, PO Box 9514, 2300 RA Leiden, The Netherlands \\ ${ }^{2}$ Research Fellow, FFPRI, Tsukuba, Ibaraki, Japan \\ 3Formerly of Dokkyo University, Soka, Saitama 340-0042, Japan \\ 4CNRS-CRCAO, East Asian Civilization Research Centre, 52 Rue du Cardinal Lemoine, 75005 Paris, France \\ 5Center for Obsidian and Lithic Studies, Meiji University, Kanda-sarugaku-cho 1-6-3, Chiyoda, Tokyo 101-oo64, Japan \\ ${ }^{6}$ Formerly Curator of the Herbarium, Naturalis Biodiversity Center, PO Box 9514, 2300 RA Leiden, The Netherlands \\ *Corresponding author; email: pieter.baas@naturalis.nl \\ Accepted for publication: 19 March 2021; available online: 9 April 2021
}

\begin{abstract}
During the court journey to Edo (Tokyo) in 1826, the famous Japan explorer Philipp Franz von Siebold (1796-1866) met an old and wise mathematician, explorer, and ethnographer, Mogami Tokunai $\left(1755^{-1836}\right)$. Tokunai not only allowed Siebold to copy sensitive maps of disputed territories in Northern Japan, but also donated him a set of 45 Japanese wood samples, most of them decorated with paintings of the foliage of the trees from which the wood came, and later provided with interesting notes on their timber uses by the Ainu people in "Jezo" (or Ezo-chi, more or less equivalent with modern Hokkaido). Based mainly on earlier detailed studies by Prof. Takao Yamaguchi and Prof. Nobushige Kato, we will discuss this collection in the context of contemporary and later wood collections and its significance for forest products research in and beyond Japan. Other Japanese wood collections taken to the Netherlands by Siebold were used for the very first Ph.D. studies on wood anatomy in Leiden, and possibly also in Munich. Siebold's most important disciple Ito Keisuke (or Ito “Keiske", or “Keisuke Itoh", 1803-19o1) oversaw the decoration of a set of painted wood samples for teaching purposes in Tokyo in the $188 \mathrm{os}$. From the 1870 on onwards, Japan was actively promoting its timber resources at World Expositions in Vienna, Philadelphia, and Paris. In the latter two venues with another special type of wood collection: sections mounted on the pages of a book, possibly inspired by a concept developed by the German forestry scientist Hermann Nördlinger.
\end{abstract}

Keywords: Wood uses; Xylaria; Japan; Philipp Franz von Siebold; Ito Keisuke; world exhibitions; biohistory.

\section{INTRODUCTION}

Wood collections are known from 17th Century Europe when they formed part of Curiosity and Naturalia Cabinets. Collections of medicinal plants and other simplicia often also contained wood specimens (Baas 1981; Feuchter-Schawelka et al. 2001; Cornish et al. 2014). This study focuses on an early and unique collection of wood samples from Japan, decorated with handpainted branches and leaves of the species involved, and preserved in the collections of the Naturalis Biodiversity Center in Leiden, The Netherlands. Earlier studies on this collection are by Baas (1981), Omori (1982), Tanisawa (1983), Ishiyama (1988), and above all by Yamaguchi \& Kato (1998) who fully documented it in their series of publications on Siebold's botanical collections in special issues of the Bulletin of the Aitsu Marine Station, Kumamato University, Japan: Calanus. This paper is largely based on Yamaguchi \& Kato's publication, and dedicated to the memory of Professor Takao Yamaguchi (1937-2013; for a biography see Baba 2013) who visited Leiden 44 times to study the natural history collections made by Siebold, including the Tokunai Wood Collections. Apart from a summarized description of the Tokunai collection, we will discuss its relevance from ethnobotanical and wood utilization points of view and explore possible links with later 19th-century wood collections made in Japan for public education, research, and trading purposes. 

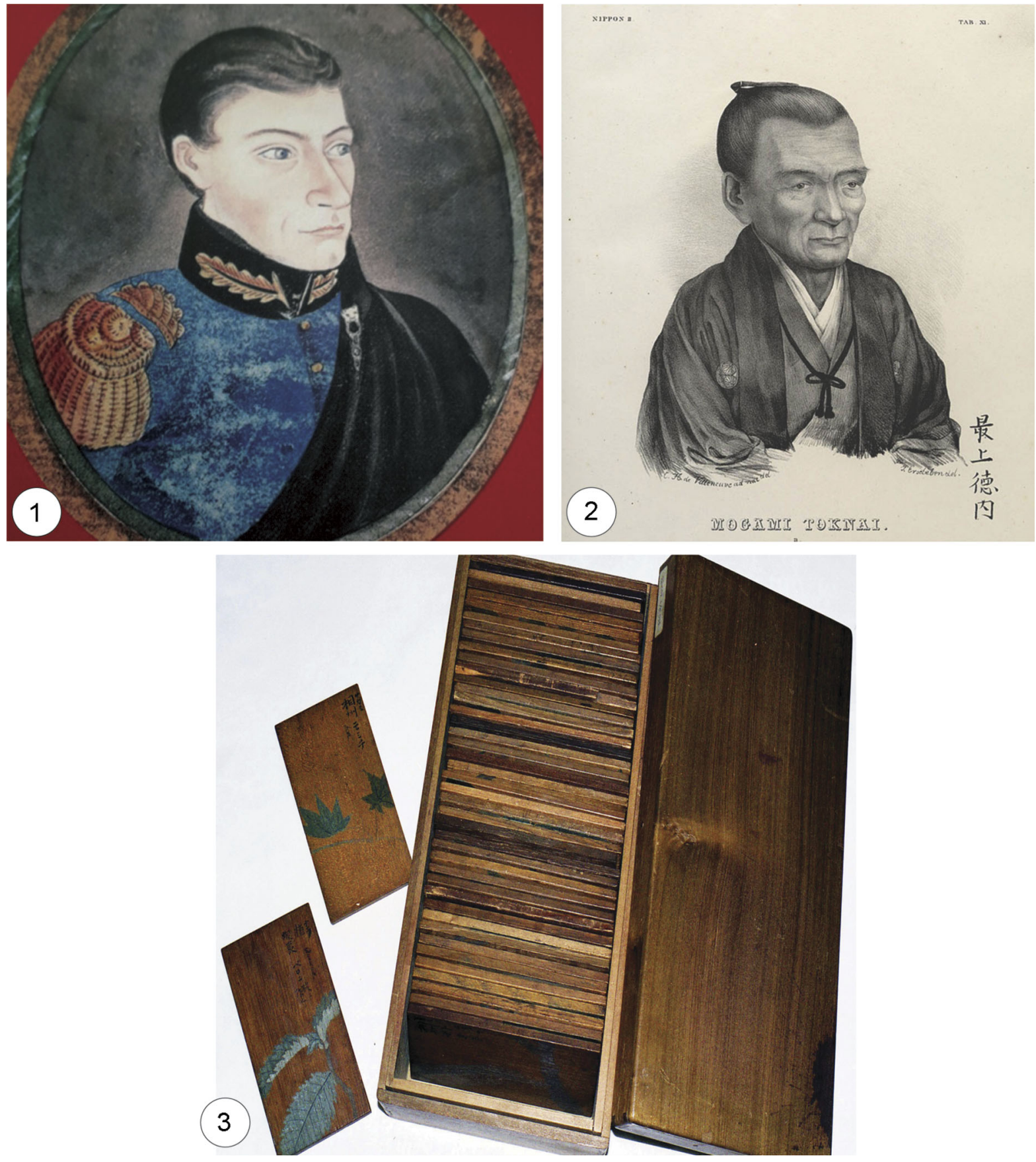

Figures 1-3. (1) Philipp Franz von Siebold, painted by Kawahara Keiga in 1824. (2) Mogami Tokunai, as depicted in Siebold's Nippon. (3) The box with 43 Japanese wood samples collected and decorated by Mogami Tokunai. Naturalis Biodiversity Center, Leiden.

\section{The decorated Tokunai wood collection}

In 1826 when Philipp Franz von Siebold (Fig. 1) took part in the so-called Hofreis (Court Journey) of the Dutch delegation from Deshima in the bay of Nagasaki to Edo, present-day Tokyo, he met an old and wise scientist, Mogami Tokunai (17551836; Fig. 2). Siebold's entry in his diary of 16 April devotes a couple of lines in Latin to this meeting. He bursts out "Dies sane calculo candidissimo notandus" — Definitely a brilliant day — "A Japanese named Mogami Tokunai showed his great ability in mathematics and related sciences. We discussed on Chinese, Japanese, and European Mathematics. Then he showed me, under the seal of secrecy, maps of oceans surrounding Jezo (or Ezo-chi, more or less equivalent with Hokkaido), and Karafto which is in dispute (= Karafuto, current Sakhalin, Russian territory since 1945). He kindly permitted me to use the maps for a while. What a great treasure". Geographical maps were a state secret in Japan, and Yamaguchia\&eKatom(1998).speculatedothat:17:31AM 
because Siebold realised this, he changed in his diary from German (not dissimilar to Dutch — in those days "the Latin of Japan", which a number of Japanese officials could perfectly read and understand) to real Latin which they could not.

During the following four weeks, Siebold and Tokunai were more or less in daily contact, and despite the fact that Siebold was extremely busy exchanging medical expertise and biological and ethnographical information with many Japanese colleagues (Siebold 1858; Oijen \& Oijen 2005) he seems to have cherished the meetings with Tokunai enormously because in his later years Siebold would often refer to his old and wise friend Mogami Tokunai (or Toknai). During one of these encounters Tokunai presented Siebold with a collection of 45 wood samples, mostly — but not all — from Jezo = Ezo-chi, mainly present-day Hokkaido, then the region of Northern Japan inhabited by Ainu people, now an endangered ethnic group, for whom Siebold showed a great ethnographic interest. The Ainu language, which did not have a script, differs from Japanese despite some similarities but is very different from Chinese. Tokunai had produced a draft Japanese-Ainu dictionary and Siebold must have picked Tokunai's brain feverishly during the few weeks of their encounter — posthumously even resulting in an Ainu-German dictionary published in Vienna by A. Pfizmaier (Yamaguchi \& Kato 1998). That dictionary also includes the plant names written in Chinese and Japanese script on the wood samples by Mogami Tokunai himself.

What makes the wood samples unique is that Tokunai painted the leaves of the trees from which the samples came on them (Yamaguchi \& Kato 1998). Tokunai also calligraphed the Ainu and Japanese names on the samples, and their uses on some of them. On the reverse side, most samples contain notes on the traditional uses by the Ainu people; most of them in German by Siebold himself, while others have labels in a different hand in Dutch (sometimes with linguistic mistakes) presumably by Japanese pupils or assistants. In later life Siebold incorporated these notes in his most important publications: (1) Nippon (Siebold 1858) and (2) Flora Japonica (Siebold \& Zuccarini 1835-1870), plus miscellaneous published and unpublished reports on Jezo and the Ainu culture.

In 1830, together with many other collections, the 45 wood samples were sent by Siebold to the Rijksherbarium, then just founded in Brussels, in one of the two crates of which the contents were to be hotly contested between herbarium director C.L. Blume and the Dutch Government on the one hand, and Siebold on the other, as to whether they belonged to Siebold or the Dutch State (Yamaguchi 1997; Thijsse 2005; Compton \& Thijsse 2013).

Tokunai's collections lived an obscure life in the Rijksherbarium until the mid-19oos when the then director decided that wood collections did not really belong in a Herbarium, and donated them to the Department of Botany of Leiden University. There they sat among the teaching collections in the room where student demonstrators of the practical courses in plant anatomy would prepare their classes. In 1969 one of us (PB) had been appointed in a double function as a researcher of systematic wood anatomy at the Rijksherbarium, whilst carrying out teaching duties in the Department of Botany. Nobody knew where the highly decorative wood collection (Fig. 3) came from or what its significance was. At the Rijksherbarium, it's then-director C.G.G.J. van Steenis (1901-1986) told his staff the fascinating story of Siebold's confinement under house arrest by the Dutch Opperhoofd of Deshima in 1828 and 1829, and his long letter to the Minister of the Interior of 1864 complaining about the dreadful way he and his collections had been treated by Blume in the past (Ishiyama 1988; Compton \& Thijsse 2013). PB asked Professor van Steenis to see a copy of the letter, and then the penny dropped: at the end of the letter Siebold lists the contents of two contested crates, and there is the clear reference to " 45 wood samples from Jezo, polished and painted with names in Ainu and Chinese". The collection in the botany department contained only 43 specimens, two had apparently been lost.

The Tokunai specimens were repatriated once again from the Botany Department to the Rijksherbarium, now an integral part of the Naturalis Biodiversity Center, and have ever since attracted the attention of Japanese scholars and have taken pride of place in exhibitions on Siebold and Japan in Rotterdam, Leiden, Tokyo, Bando (Ibaraki), and Berlin. Some specimens are semi-permanently exhibited in the Japan Museum Siebold Huis in Leiden.

\section{Who was Mogami Tokunai?}

Yamaguchi \& Kato (1998) give a brief but well-documented biography of Mogami Tokunai (1755-1836). A very extensive biography is by Shimaya (1977, in Japanese). Tokunai was born as the son of a poor farmer, largely self-taught and his scientific education in Edo (Tokyo) did not start until he was 26 years old. Following a medical training, he turned to mathematics and became a student of the scholar Honda Toshiaki (= Honda Rimei, 1730-1820), who also kindled his interest in astronomy, geography, economics, and technology. In 1785 Tokunai was asked to replace his sick teacher on a mission to the northern districts of Japan. He actively explored Jezo (Hokkaido) and some Kuril Islands, Russian territory since 1945. He also developed a keen interest in the inhabitants of Hokkaido - the Ainu people and their culture and paid a total of eight or even ten visits to Hokkaido (Shimaya 1977; Yamaguchi \& Kato 1998).

Despite the fact that Tokunai and others were arrested by the Tokugawa government during his third visit to Hokkaido, suspected of collaboration with a convicted explorer, Tokunai gradually becameval well-respected expert $20 f_{2}$ the northerm 
Table 1.

Woods collected by Tokunai in Hokkaido and their uses as noted in German or Dutch on the wood samples and/or in Nippon (Siebold $1858)$.

\begin{tabular}{|c|c|}
\hline Species and sample number & Uses \\
\hline Abies sachalinensis (F. Schmidt) Mast. ${ }^{1}$ (203) & Building of Ainu huts \\
\hline Acer amoenum Carrière var. amoenum (202) & Handles of knives and swords \\
\hline Alnus hirsuta (Spach) Turcz. ex Rupr. ${ }^{2}(184)$ & Firewood, bark dye \\
\hline Betula maximowicziana Regel $^{3}$ (177) & Bark for packing and torches, wood for ladles \\
\hline Castanea crenata Sieb. et Zucc. (189) & No wood uses mentioned \\
\hline Cercidiphyllum japonicum Sieb et Zucc. (195) & Weak wood for shipbuilding \\
\hline Euonymus sieboldianus $\mathrm{Bl} .(208)$ & Ladles in canoes \\
\hline Fraxinus mandshurica Rupr. (190) & Shipbuilding \\
\hline Juglans mandshurica Maxim. (205) & Various uses \\
\hline Kalopanax septemblobus (Thunb.) Koidz. (207) & Dugout canoes \\
\hline Magnolia kobus DC (204) & Firewood \\
\hline Magnolia obovata Thunb. (185) & Arrow boxes (quivers) \\
\hline Morus australis Poir. $^{4}$ (200) & Snowshoes \\
\hline Phellodendron amurense Rupr. (191) & Bark used for roofs \\
\hline Picea jezoensis (Siebold et Zucc.) Carrière ${ }^{5}$ (183) & Very weak wood, arrows, utensils \\
\hline Pinus parviflora Sieb. et Zucc. (199) & House- and shipbuilding \\
\hline Populus suaveolens Fisch. $^{6}$ (192) & No wood uses mentioned \\
\hline Quercus crispula Blume (218) & Oars and ruthers. Kuruma culture \\
\hline Quercus dentata Thunb. (198) & Ship utensils \\
\hline Salix sp. ${ }^{7}(187)$ & Inaw (religious tool) \\
\hline Salix sp. ${ }^{8}(197)$ & Inaw (religious tool) \\
\hline Sorbus alnifolia (Siebold et Zucc.) K. Koch ${ }^{9}$ (186) & No wood uses mentioned \\
\hline Sorbus commixta Hedl. (196) & Wood carving \\
\hline Syringa reticulata (Blume) Hara $^{10}(193)$ & No wood uses mentioned \\
\hline Taxus cuspidata Sieb. et Zucc. (216) & Bows \\
\hline Tilia japonica (Miq.) Simonk. ${ }^{11}$ (2O1) & Bark fibres for sails and ropes \\
\hline Ulmus davidiana Planch. ${ }^{12}(217)$ & Roots for tinder, wood utensils \\
\hline
\end{tabular}

Y\&K in notes refers to Yamaguchi and Kato (1998).

${ }^{1}$ Abies homelepis var. tokunaiae Carrière, mentioned by $\mathrm{Y} \& \mathrm{~K}$ is a synonym.

${ }^{2}$ Alnus japonica is less likely.

${ }^{3}$ Betula platyphylla according to Y\&K, who also noted that leaf margin morphology does not match Betula.

${ }^{4} M$. bombycis as suggested by $\mathrm{Y} \& \mathrm{~K}$ is a synonym of $M$. australis.

${ }^{5}$ Abies jezoensis Sieb. et Zucc according to Y\&K is a synonym.

${ }^{6}$ Listed as Populus maximowiczii in Y\&K.

${ }^{7}$ Salix bakko according to Y\&K. This is a synonym of $S$. caprea $\mathrm{L}$.

${ }^{8}$ Salix rorida Laksch. according to Y\&K, see text.

${ }^{9}$ Unidentified in Y\&K. Aria alnifolia Sieb. et Zucc.) Decne. is a synonym.

${ }^{10}$ Listed as Euonymus sp. in Y\&K.

${ }^{11}$ Tilia maximowicziana Shiras according to Y\&K.

${ }^{12}$ Carpinus laxiflora according to $\mathrm{Y} \& \mathrm{~K}$ is impossible, see text.

districts. He was also an advocate of the Ainu interests and a staunch critic of the attitudes of local Japanese rulers, and the lack of action by the central Japanese government. He studied the Ainu language and culture in great detail. In between his activities in Hokkaido he was also engaged in forestry on behalf of the Tokugawa government in various districts of Japan. In 1790 he was appointed as an official for building and civil engineering. According to Yamaguchi \& Kato (1998), the specimens Tokunai presented to Siebold in 1826 were probably collected during an expedition to Hokkaido in 1799. Tanisawa (1983) produced a map of localities in SE Hokkaido where each individual wood sample came from — and assumed a collecting year of 180o. Yamaguchi \& Kato (1998) considered that Tokunai went out of his way to pass his knowledge of the natural history, ethnography, and geography of Hokkaido and the Ainu people on to Siebold in 1826, in the hope to get it published.

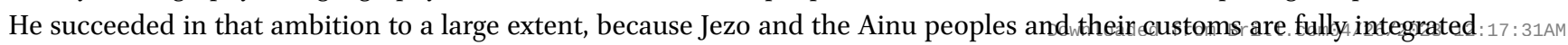



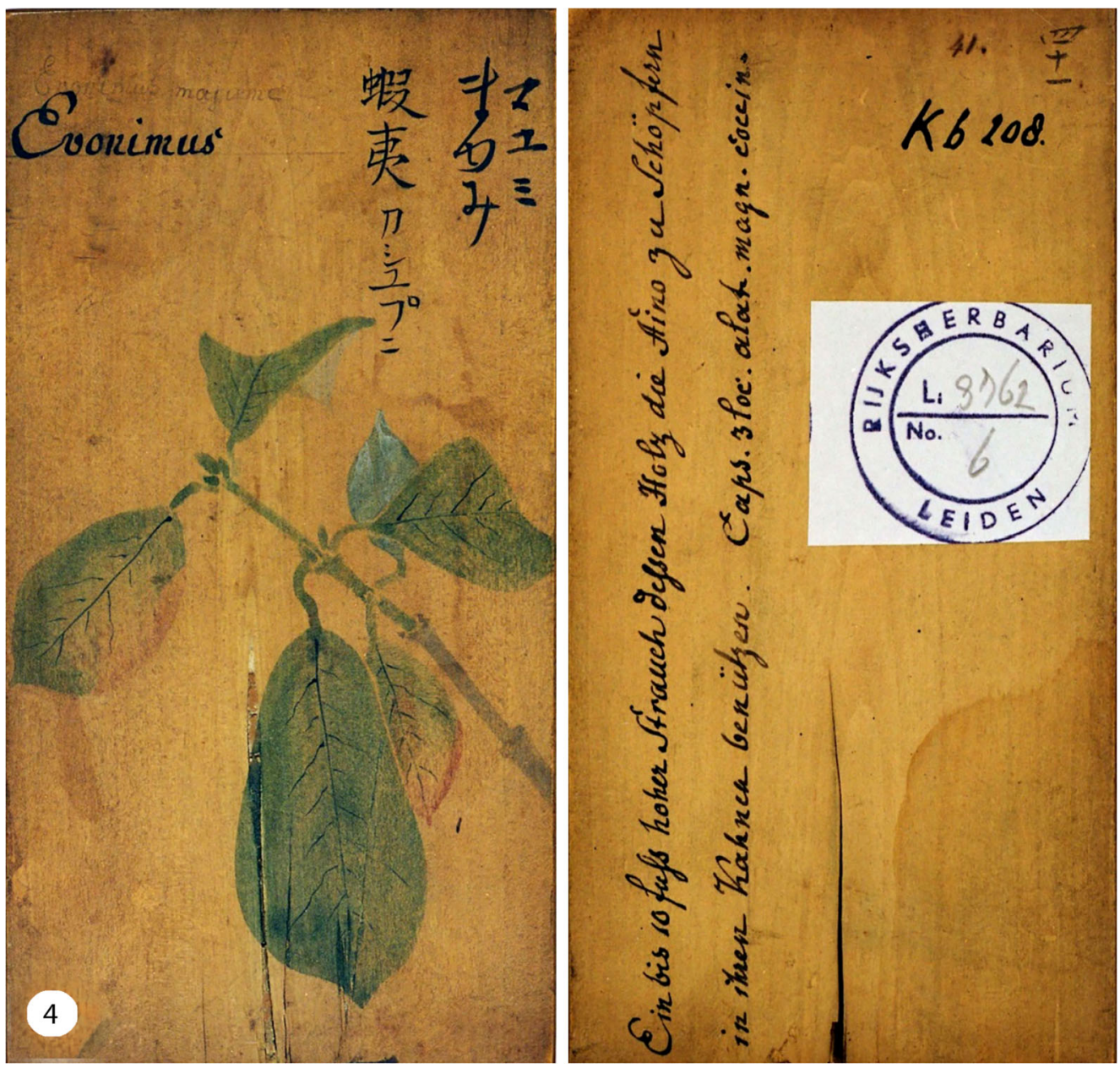

Figure 4. Euonymus sieboldianus. Front and reverse of wood sample Kb2o8.

into Siebold's later most important publications Nippon, and Flora Japonica, and his preparatory work for an Ainu-JapaneseGerman dictionary. Siebold (1858) included a portrait of Tokunai by Kawahara Keiga, copied by C.H. de Villeneuve, in Nippon (Fig. 2).

\section{What did Tokunai tell Siebold about the timbers and their uses?}

The most direct and comprehensive knowledge on what Siebold learned from Tokunai can be read in the substantial chapter Siebold (1858) devoted to Jezo (Hokkaido) on pp. 235-270 of volume II of "Nippon". Here he acknowledged Mogami Tokunai and his Japanese-Ainu Language dictionary as his main source of information. The geographer Mamiya Rinzo (178o1844) has been credited as another important source of information for Siebold (Kouwenhoven \& Forrer 200o). The Ainu people or "Ostwilden" — "the Wild ones from the East" — are described by Siebold as a fairly rough and primitively cultured people, whose women breastfed baby bears, which were subsequently eaten as a delicacy (however, the status of bears as deities in Ainu religion is not mentioned). The women are also said to be good at skipping (rope jumping). The great diversity of the flora of Jezo is highlighted, together with its affinities with the floras of Siberia, North China, and North America. Special attention is given to the description of about 15 timber-producing tree species, for which uses are given, often in the same words as Siebold's annotations on the reverse of the hand-painted Tokunai wood samples.

Of the 45 hand-painted samples, two were lost, 14 are from Soshu in the present Kanagawa prefecture, not far from Tokyo; two are from unknown provenance, and 27 are from Hokkaido and have annotations on their uses. Flora Japonica- never completed- has treated only a few timber species from Hokkaido, but of the few species that also occur so far north, Siebold this time in French - repeated Tokunai's information as written on the wood samples, almost verbatim.

A list of the 27 Hokkaido samples, with notes on their uses, either annotated on the wood samples or documented later in Siebold's Nippon and Flora Japonica is given in Table 1. For a full photographic and transliterated documentation of all wood samples, the reader is referred to Yamaguchi and Kato (1998) and to Tables Al din the Appendix of this paper . During 

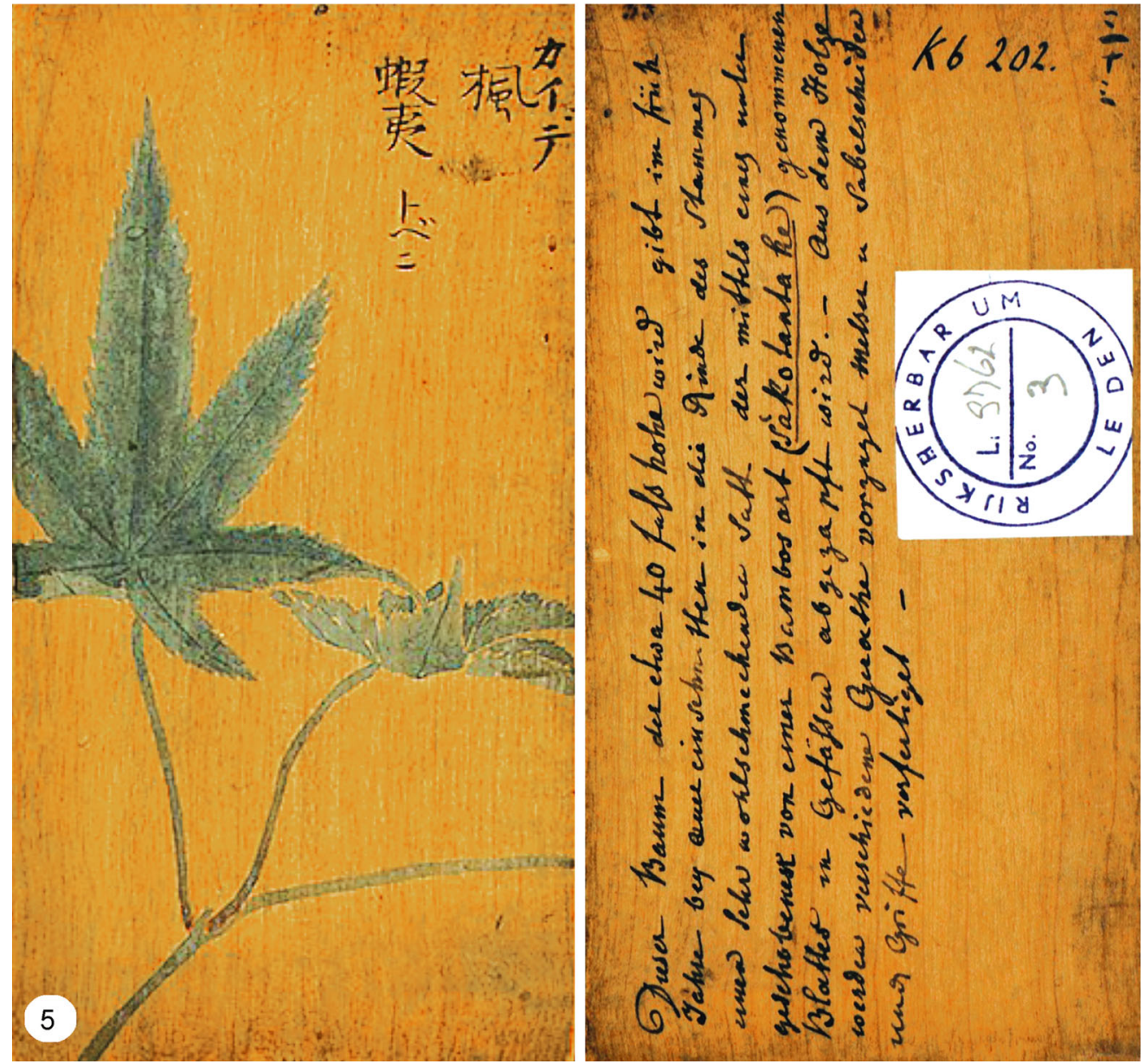

Figure 5. Acer amoenum var. amoenum. Front and reverse of wood sample Kb2O2.

the study for this paper, we found that some identifications in Yamaguchi \& Kato (1998) are doubtful, and we have amended them accordingly (see footnotes to Table 1). However, some of the identifications remain uncertain because (1) the rather sketchy paintings only convey a limited number of characters of the trees that were sampled; (2) the identifications based on oral knowledge transfer by the Ainu informants of Tokunai, and translated into Japanese vernacular names may have been mistaken or confused; and (3) specimens may have become mixed up before they even were painted or annotated. The latter two sources of error occur quite regularly in institutional wood collections to this day. It would be desirable to non-destructively study the wood anatomy of the Tokunai samples with Micro-CT scanning to settle some of the remaining problems (as done, for instance, by Wheeler et al. 2020).

A selection of samples is pictured (Figs 4-13) and discussed below. The samples measure $138 \times 73 \mathrm{~mm}$ and are about $6.5 \mathrm{~mm}$ thick.

Euonymus sieboldianus Blume (Fig. 4, sample $\mathrm{Kb} 208$ ) - a relative of the spindle tree or louseberry (kardinaalsmuts in Dutch); Siebold's annotation mentions that it is a shrub up to 10 feet tall, of which the wood is used to make ladles (Schöpfer) to be used in the canoes by the Ainu people. Interestingly the Ainu name for this species Kasupni refers to this use: Kasup = ladle. Other Euonymus species also occurring in Hokkaido: E. macrapterus Rupur., E. oxyphyllus Miq. or E. sachalensis (F. Schmidt) Maxim. (synonyms: E. planipes (Koehne) Koehne and E. tricarpus Koidz.) have different Ainu names, referring to different uses.

Acer amoenum Carrière var. amoenum (Fig. 5, sample Kb 202). In Nippon, Siebold (1858) referred this species to Acer saccharinum, the North American sugar maple. This Japanese look-alike has a very full annotation by Siebold about the tapping of its trunk for the well-tasting maple sap in spring and assembling that sap in a bamboo leaf (in later texts by Siebold bamboo leaf is changed into the more plausible bamboo beaker). The wood is said to be used for several utensils, mainly handles or shafts of knives and swords. One may wonder whether Tokunai and/or Siebold confused,the sap producing attributes:from: 17:31AM 

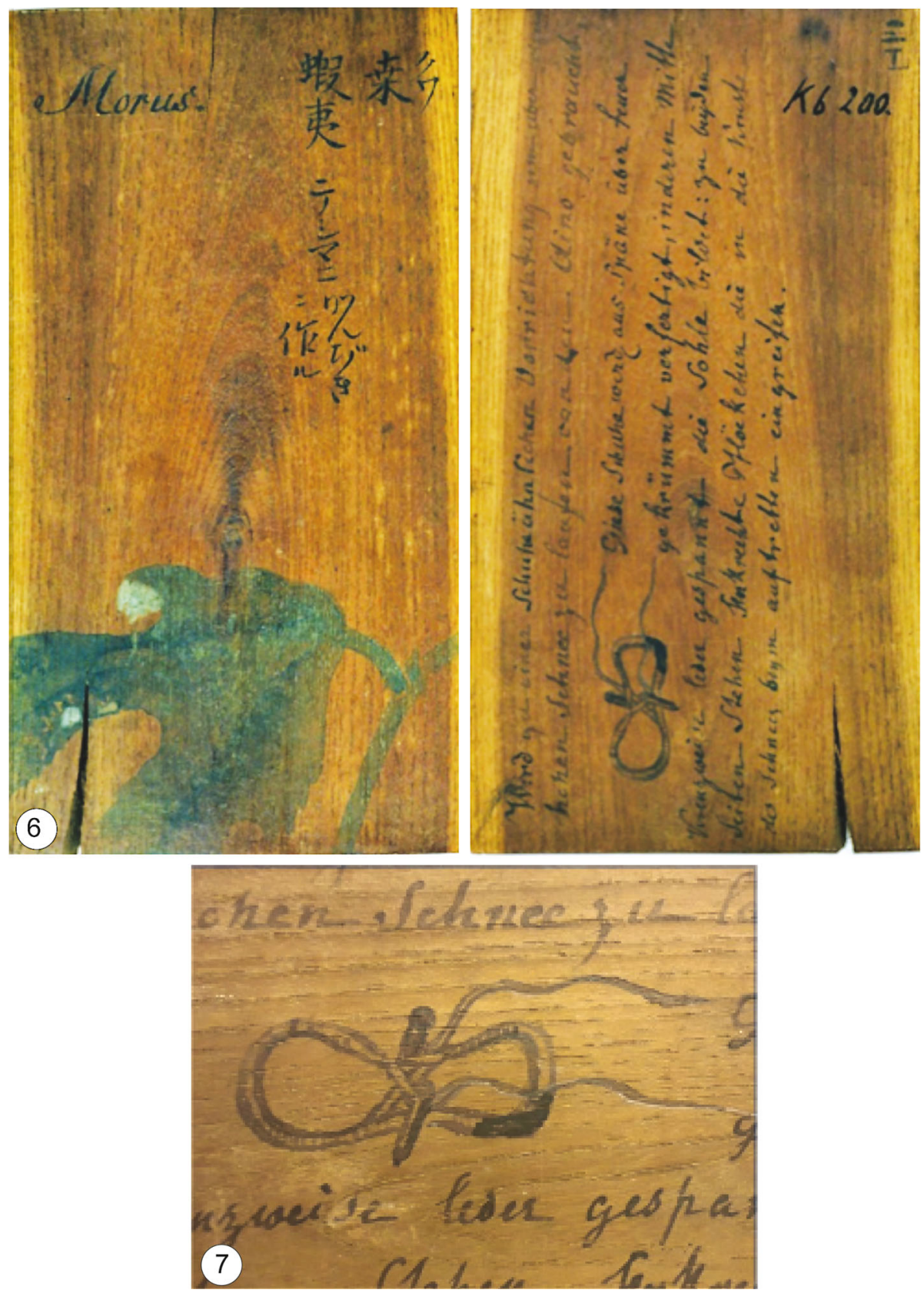

Figures 6-7. Morus australis. (6) Front and reverse of sample Kb 20o, and (7) detail of drawing of a snowshoe made of its wood.

another species, A. pictum Thunb., a maple species still used for maple sap tapping in Hokkaido, but with a different leaf margin morphology from the painting on the wood sample.

Morus australis Poir (syn. M. bombycis Koidz.) (Figs 6 and 7, sample $\mathrm{Kb}$ 200). This mulberry species has very dark heartwood. Siebold noted that it is favoured by the Ainu people to make snowshoes, which are described and illustrated in great detail. Wood sticks are bent over fire and attached to the feet by leather laces, with small sticks on both sides to keep a grip on the crusty snow. Similar snowshoes were also known from people in Siberia.

Ulmus davidiana Planch. var. japonica (Rehder) Nakai (Fig. 8, sample Kb 217). Yamaguchi \& Kato (1998) listed this wood sample as Carpinus laxiflora (Sieb. et Zucc.) Bl. but this identification must be incorrect. The wood of $\mathrm{Kb} 217$ is ring-porous, and its heartwood colour matches that of elm (Ulmus), not of hornbeam (Carpinus). The leaves resemble U. parvifolia rather than $U$. davidiana. However, the Japanese name on the wood sample "Aka-damo" corresponds with U. davidiana. Siebold annotated this specimen with an unexpected use: its roots are used as tinder sticks for making fire. Blowing on the glowing end of the sticks will set other wood ablaze ("Zunder, die Flammer dem einem Ende dereHolzstöakchemdurch/einblasen zum 

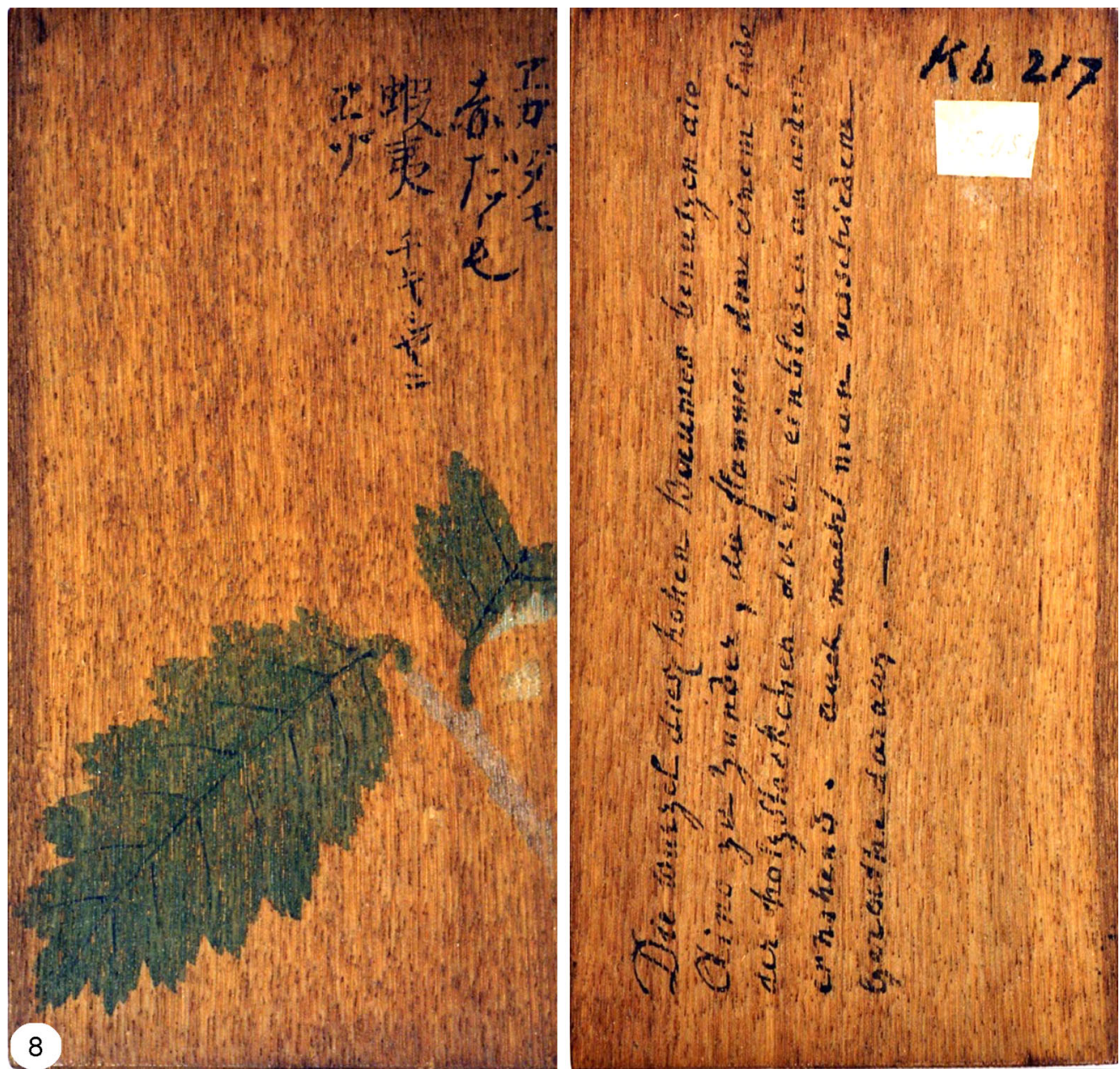

Figure 8. Ulmus davidiana var. japonica. Front and reverse of wood sample Kb217.

andern ernähernd"). Furthermore, the wood is said to be used for utensils. In Nippon Siebold refers to the vernacular name Tsjikisjani (= Cikisani) in Ainu and considers it "eine Lorbeer-Art (?)", a species of Laurus or Lauraceae in general — again a wood anatomical and leaf morphological mismatch. Tsjikisjani refers to the fire-making properties of tinder.

Magnolia obovata Thunb. (Fig. 9, sample Kb 185) used for making arrow boxes (quivers, "pijlkokers" in Dutch). Here the Dutch annotation clearly shows that this collection of woods from Hokkaido was used to complete a dictionary of the Ainu language. How else to explain the very elementary text: "One usually makes from this wood the arrow-box. Arrow box is a box in which one keeps the arrow". The Ainu name "ikayupuni" contains the syllables "pu(s)" = quiver and "ni" = tree.

Kalopanax septemblobus (Thunb.) Koidz (synonyms K. pictus (Thunb.) Nakai and Panax ricinifolia Sieb. et Zucc.) (Fig. 10, sample $\mathrm{Kb}$ 207), a big tree of which the trunk is used for dug-out canoes. On the wood sample, Aralia and Bignonia are both indicated as possible identities. In Siebold's handwriting on the reverse side, it is said to be "not unlike Aralia pentaphylla according to its leaves". This must be a mistake because Aralia has compound and not lobed leaves like Kb 207. In Nippon Siebold doubtfully assigned this wood to Catalpa or Paulownia. The identification as Kalopanax is also doubtful, on account of the petiole attachment to the lamina in the painting.

Picea jezoensis (Sieb. et Zucc.) Carrière var.jesoensis, Jezo spruce (Fig. 11, sample Kb 183), was still labelled as Abies jezoensis Sieb. et Zucc., (Jezo fir), by Siebold (1858) and Yamaguchi \& Kato (1998), but the latter name has meanwhile been put into synonymy. This wood sample is annotated to be used in Hokkaido and Sakhalin to make arrows and "most other utensils". The wood is very weak- and here Siebold directly acknowledges in his handwriting that he knows this from M. Toknai. Note that an offcut was taken at one of the corners of this wood sample for anatomical research in the 2oth century.

Taxus cuspidata Sieb. et Zucc. (Fig. 12, sample Kb 216), "a yew species up to 10 feet high" (in reality this species can grow up to $20 \mathrm{~m}$ ) was used by the Ainu people for making bows in archery; a very common traditional use also of other Taxus species in Europe and North America of this highly elastic and tough wood. 

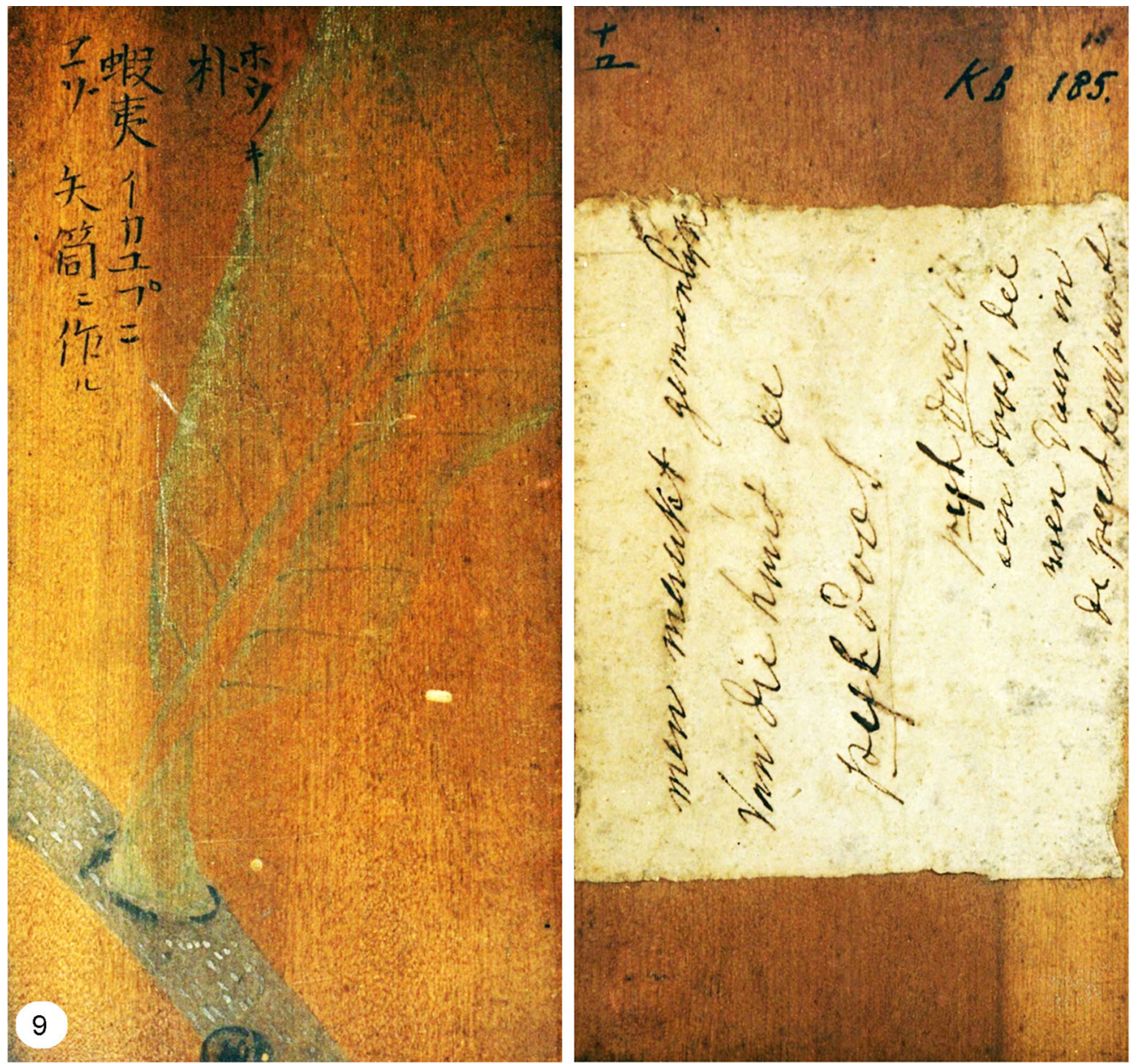

Figure 9. Magnolia obovata. Front and reverse of wood sample Kb185.

Salix sp. (Fig. 13, sample Kb 197). This willow species was identified by Yamaguchi and Kato (1998) as S. rorida Laksch. On the reverse side of the sample, a label has been glued with an illegible Dutch text, which can partly be deciphered when consulting the description in Nippon. The drawing refers to a religious utensil called Inaw (or Inao): whittled willow prayer sticks with pendent, curl-like shavings used to mark graves and houses (Siebold 1832). Heinrich von Siebold (1852-1908), one of Siebold's sons, later collected several Inaw, which are now in the Ethnographic Weltmuseum in Vienna, Austria (https://www.rekihaku.ac.jp/up-cgi/login.pl?p=param/pfvs_en/db_param\&lang=en). Intriguingly, the annotations on the label in Figure 13 also refer in Japanese characters to another religious utensil a heisoku- superficially resembling Inaw or a bunch of Inaw but made of rope paper. Another willow species Salix bakko Kimura, is apparently also used for Inaw according to Yamaguchi \& Kato (1998), but the label in Dutch for that species (specimen Kb 187) says that this is "een onnoodige hout": a useless wood. The species identifications within Salix should probably be considered tentative at best. In the Ainu language, the word susu or sjusju denotes willows in general. Possible species with identical wood and similar leaf morphology in Hokkaido are S. miyabeana Seeman, S. pet-susu Kimura, S. rorida Laksch., or S. sachalensis F. Schmidt.

\section{Ethnobotanical significance}

We have of course asked the question of whether the Tokunai samples and wood uses recorded show a highly selective pattern, unique to the Ainu culture. For that purpose, we have compared the list of Tokunai samples with general inventories of useful Japanese timbers by Geerts (1876), Anonymous (1949, 1987), and Mertz (2016, 2020) and personal communications from T. Itoh, S. Noshiro, and T. Fujii. It appears that the list of Tokunai wood samples from Hokkaido shows much overlap with general lists of useful Japanese timbers, especially at the level of genera (results of the comparisons not shown). Unsurprisingly the most popular Japanese timbers sugi (Cryptomeria japonica) and hinoki (Chamaecyparis obtusa) are lacking because these species do not occur as far north as Hokkaido and Sakhalin. 

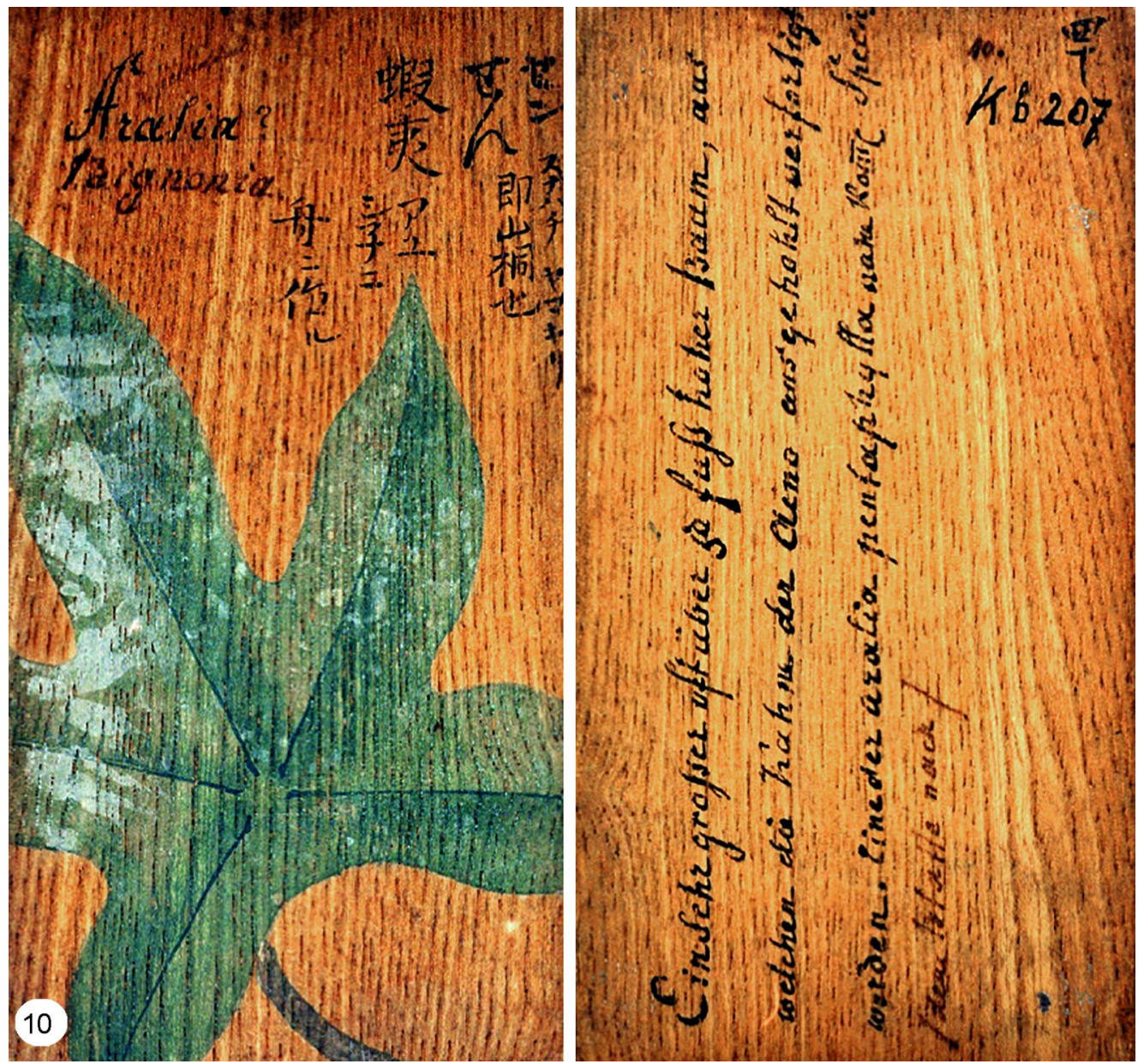

Figure 10. Kalopanax septemlobus. Front and reverse of wood sample Kb207.

One can easily be tempted to consider the annotations of wood uses on the Tokunai samples from Hokkaido as evidence of a sophisticated wood culture, bearing testimony of selective wood use for highly specialized end products (mulberry for snowshoes, elm rootwood for making tinder, yew for bows, spruce for arrows, Magnolia wood for quivers). However, we must not forget that Tokunai's relatively small wood collection can only give an incomplete picture. A more recent inventory of traditional Ainu wood uses (http://www.ainu-museum.or.jp/siror/dictionary/ (in Japanese)) shows that for several special end uses other woods were employed as well — probably depending on local availability. For instance, snowshoes were not only made from Morus wood, but also from Taxus cuspidata; the Inaw or prayer sticks were not only made of willow (Salix sp.) but also of Phellodendron amurense and Cornus controversa. Arrows were made of a range of species including Euonymus oxyphyllus, Morus australis and Picea jezoensis. Thus, the selection of woods for several uses was less specific than apparent from the Tokunai collection. A more detailed analysis of the Ainu wood culture should take into account large numbers of historical Ainu artefacts because traditional Ainu wood uses have largely disappeared due to the assimilation of the Ainu with the Japanese peoples and cultures.

\section{Impact and other wood collections by Siebold and his sons}

The impact of the samples from Hokkaido must have been very limited in the first decades after Siebold's return to Europe in 1830 when Siebold and the Rijksherbarium Director C.L. Blume were at loggerheads about the property rights of the contents of two sealed crates, one of which contained the wood samples. The hand-painted wood samples were erroneously catalogued by Blume's successor Miquel (1870), but other undecorated wood collections sent by Siebold from Japan (Yamaguchi 1997) were used for research by one of the few Ph.D. students of Miquel's successor W.F.R. Suringar: Ludovicus Posthumus, who took his Ph.D. degree in 1874 on a flimsy and undistinguished microscopic study of 73 Japanese woods, including the specimens pictured in Figure 14. 

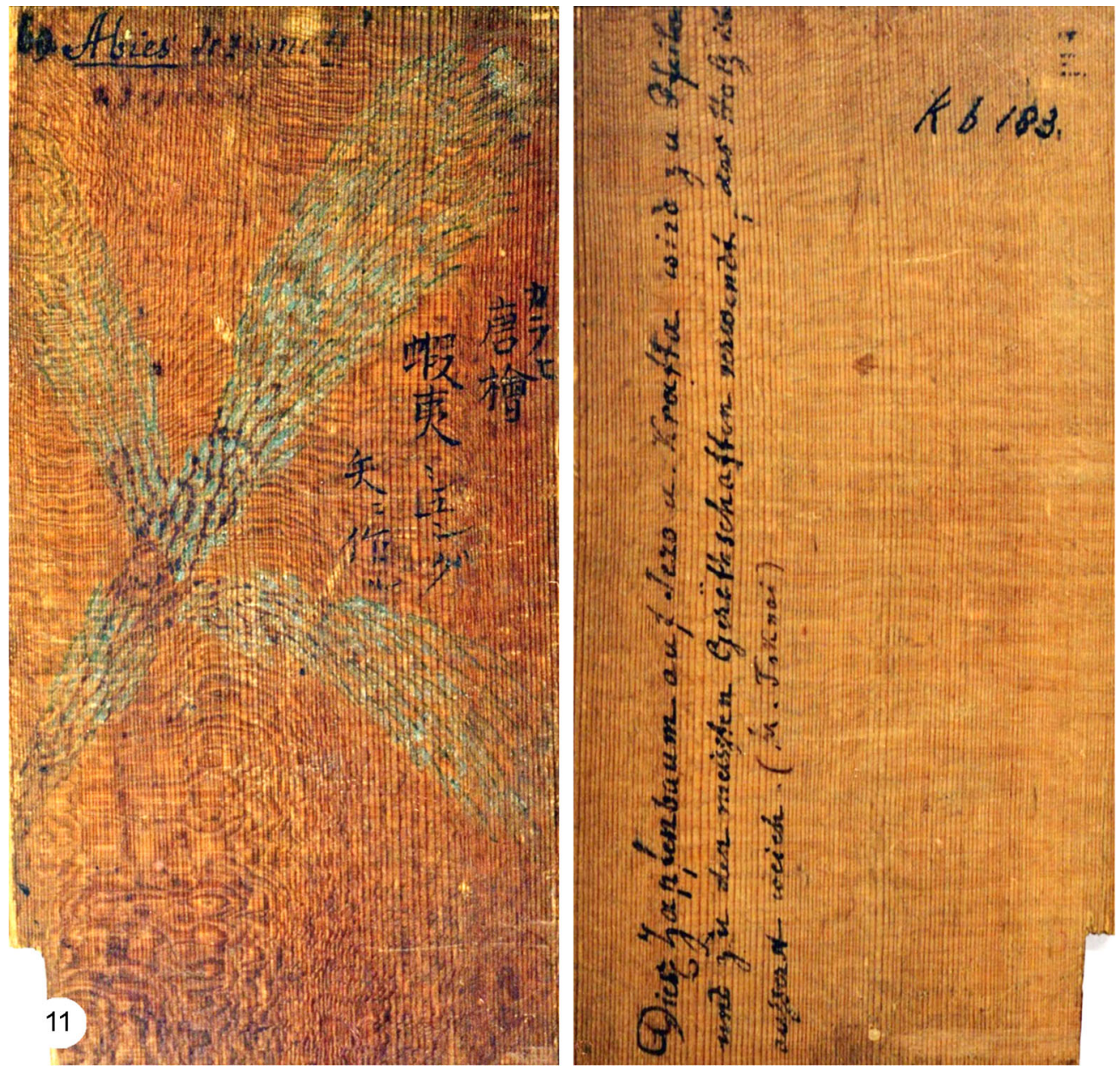

Figure 11. Picea jezoensis var. jesoensis. Front and reverse of wood sample Kb183. Note that offcut was taken for anatomical study.

The first-ever wood anatomist from Japan, Nakamura Yaroku, a pupil of the famous botanist Theodor Hartig, defended his Ph.D. Thesis in Munich in 1882 (Nakamura 1882) on 22 Japanese softwoods - according to Sudo (2007) possibly also using samples sent earlier by Siebold to Europe, either following his first visit from 1823 to 1829 or the second one from 1859 to 1862 . Two samples of the Tokunai collection from Hokkaido show signs of small subsamples taken for anatomical study by BSc students in the mid-2oth century (Fig. 11: Kb 183, Abies jezoensis (= Picea jezoenzis)) and $\mathrm{Kb} 203$, Abies homolepis apparently to find anatomical differences between Japanese Picea and Abies species. As a student assistant in the 196os, PB has seen the unpublished reports of these studies, which alas have meanwhile been lost. The reports formed part of a large collection of so-called "houtverslagen" (wood reports), mini monographs on the wood anatomy that students of biology had to prepare for the fulfillment of their degree. The real impact of Tokunai's samples outside Japan had to await their rediscovery in the 1970 s when they started their life as attractive museum pieces sent out for display at various international exhibitions.

Meanwhile, in Japan, wood collections and wood science in the 19th century flourished in a way that might have had some of their roots in the Siebold school. Siebold himself was instrumental in sending significant wood collections to the Netherlands. His shipments which arrived in Brussels in 1830 together with the hand-painted Tokunai specimens also included 225 specimens of low diameter stems with bark attached and with Latin names inscribed by Siebold, and 86 specimens with Japanese inscriptions only, now preserved in the Naturalis Wood Collection in Leiden. The World Culture Museum of Leiden (formerly Ethnology or Volkenkunde Museum) contains about 45 wood samples of assorted shapes and sizes (Tsukahara \& Osawa 1989; Yamaguchi 1997). The Museum of Five Continents in Munich has a collection of 34 standard size wood samples by Siebold and a number of other wood items, probably resulting from Siebold's second visit to Japan from 1859 to 1862 . This collection had also been exhibited by Siebold in Amsterdam during a Japan Exposition in 1863 (Siebold 1863). Very interestingly, the Weltmuseum in Vienna preserves 11 commercial wood samples marked with Japanese characters, and a disk of a liana (probably Wisteria), together mounted on a larger board and some wooden artefacts, including the religious prayer sticks, Inaw, made of willow, and donated by Siebold's son Heinrich (1852-1908). Heinrichliweddanditravelledextensively in Japany 

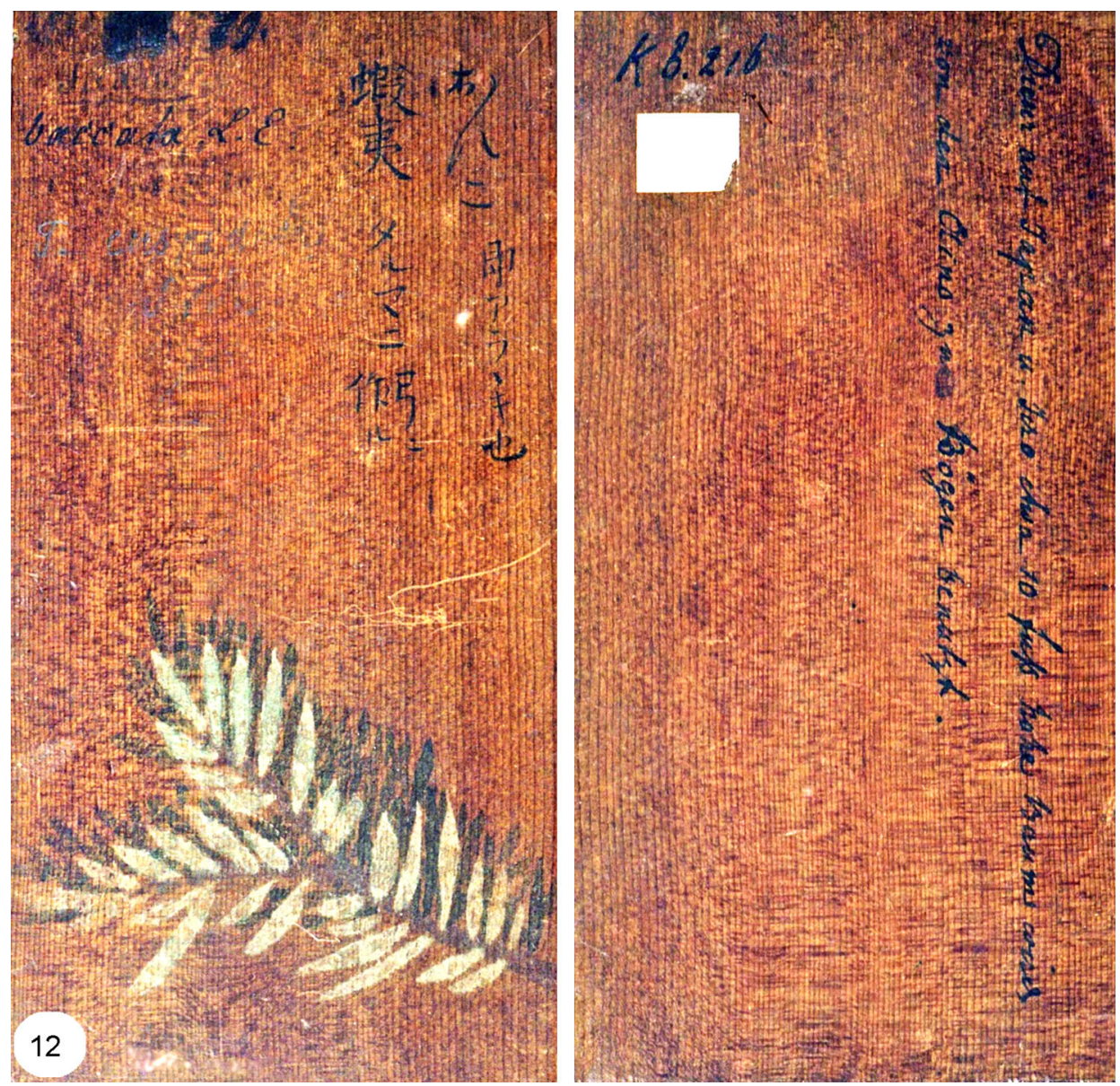

Figure 12. Taxus cuspidata. Front and reverse of wood sample Kb 216.

and also visited Hokkaido and studied the Ainu people and their culture. He was a diplomat and official translator in the Austrian-Hungarian government service and was also closely involved in preparing the Japanese contribution to the Vienna World Exhibition of 1873 (Körner 1967; Mertz 2020). His brother Alexander (1846-1911) was also on the organizing committee but in the Japanese government service. After the exhibition, Japanese collections (mainly non-wood) were sorted out by Heinrich and Alexander and given to various institutions, including the Museum für Kunst und Technik in Vienna (a predecessor of the current World Museum), making these samples and artefacts possibly remnants of that first World Exhibition with Japanese artefacts (the collections and Inaw can be viewed on the website cited above).

\section{Ito Keisuke and his botanical network}

Ito Keisuke (1803-19o1), Siebold's most important student, but also a colleague in his own right, became very influential in Japanese Botany, Forestry, and Medical Science during his very long and distinguished career. In 1839 he was involved in the selection of timber for rebuilding the Shogun Palace in Tokyo after it had been burnt down (Geerts 1883). From 1861-1863 he was charged by the Tokugawa government with the promotion of domestic products for foreign trade, and in 1870 he was ordered by the Meiji government to prepare a domestic exhibition in Tokyo, as an upbeat for the Vienna World Expo in 1873 (Kanayama 1999). As the first director of the Koishikawa botanical garden in Tokyo, he supervised the painting with very fine botanical illustrations of over two hundred wood boards by Kato Chikusai (and his team?), the botanical artist in the service of the botanical garden (Nagata et al. 2013). Although completely different in style, scope, and purpose, this unique collection covering ca. 15 o species may well have taken inspiration from Tokunai's samples, which Ito Keisuke probably had seen in 1827 and 1828 when assisting Siebold on Deshima. The boards were commissioned by the first President of the University of Tokyo in 1878 and found their way to Berlin (the Botanical Museum of the Berlin-Dahlem Garden), Kew, Harvard, and some private collections (Nagata et al. 2013), where they were cherished, but did not have any impact on research as far as we know.

Simultaneously in this period, just after the opening up of Japan, in which Siebold and later his son Alexander were playing an active role (Körner 1967), the Japanese Empire became active in presenting its culturad and natural resources att Nationad:17:31 AM 

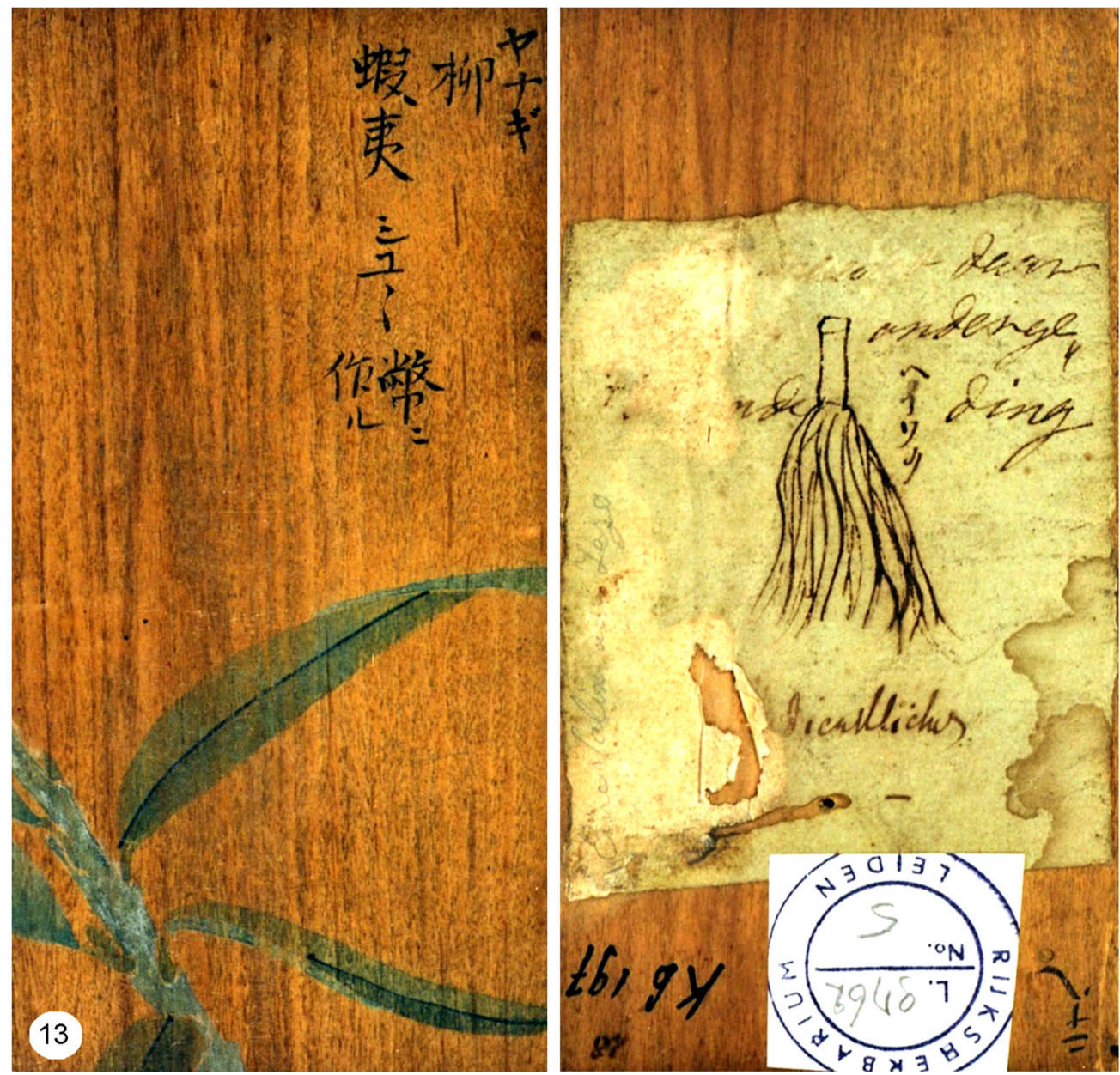

Figure 13. Salix sp. Front and reverse of wood sample Kb197 with a sketchy drawing of an Inaw (see text). Note Japanese text next to the drawing, referring to Heisoku, rope-paper offerings in Shinto shrines.

and International World Expositions. At the first one organized by Albert of Saxe Coburg, Prince Consort to Queen Victoria, in London in 1851, Japan had not yet been represented for the obvious reason that it was still closed to the West. However, in subsequent exhibitions this was different. The son's Alexander and Heinrich von Siebold were involved in the Japanese submission to the Vienna World Exposition of 1873, which also included over 130 wood samples (Anonymous 1873; Tanaka \& Hirayama 1897). In the Expos in Philadelphia (1876) and Paris (1878) Japan's submissions included a very charming collection of 100 woods, in the form of thin transverse and longitudinal sections mounted on the pages of a small book (Mertz 2020). These books entitled Yûyô Mokuzai Shôran, translated “Quick Guide to Japanese Useful Woods", were produced in high numbers, by a team of Japanese wood specialists under the guidance of Tanaka Yoshio (1838-1916), head of Natural History, working at the so-called Museum Bureau in Tokyo and later director of the Tokyo Museum (Geerts 1883), that served as Expo Secretariat to prepare the Japanese contributions to the World Expositions. Tanaka Yoshio had been a pupil, assistant, and friend of Ito Keisuke (Geerts 1883) and again it seems possible that Ito was directly or indirectly the inspiration for this initiative.

In the Botany Department of Leiden University, there was a copy of the "Quick Guide" in the library (donated by a civic engineer G.A. Escher (1843-1939), an important advisor to the Japanese Government on matters of hydraulic engineering in Japan), which is now in the library of the Naturalis Biodiversity Center. Mertz (2020) has made a thorough study of the origins and scope of these books. Representing wood collections as a collection of ultrathin veneers, as in the "Quick Guide", had precedence. Between $185^{2}$ and 1888, H. Nördlinger, Professor of Forestry in Tübingen, Germany, had produced a collection of 1100 Querschnitte (cross-sections) of world woods. His first volume had been submitted to the first World Exhibition in London and had been awarded a medal (Bubner 2008). Since the late 19th-century wood science and forestry in Japan was highly influenced by Germany (Sudo 2007) it is tempting to think that the "Quicku|Guide" was inspired by the@Quersehnitte 

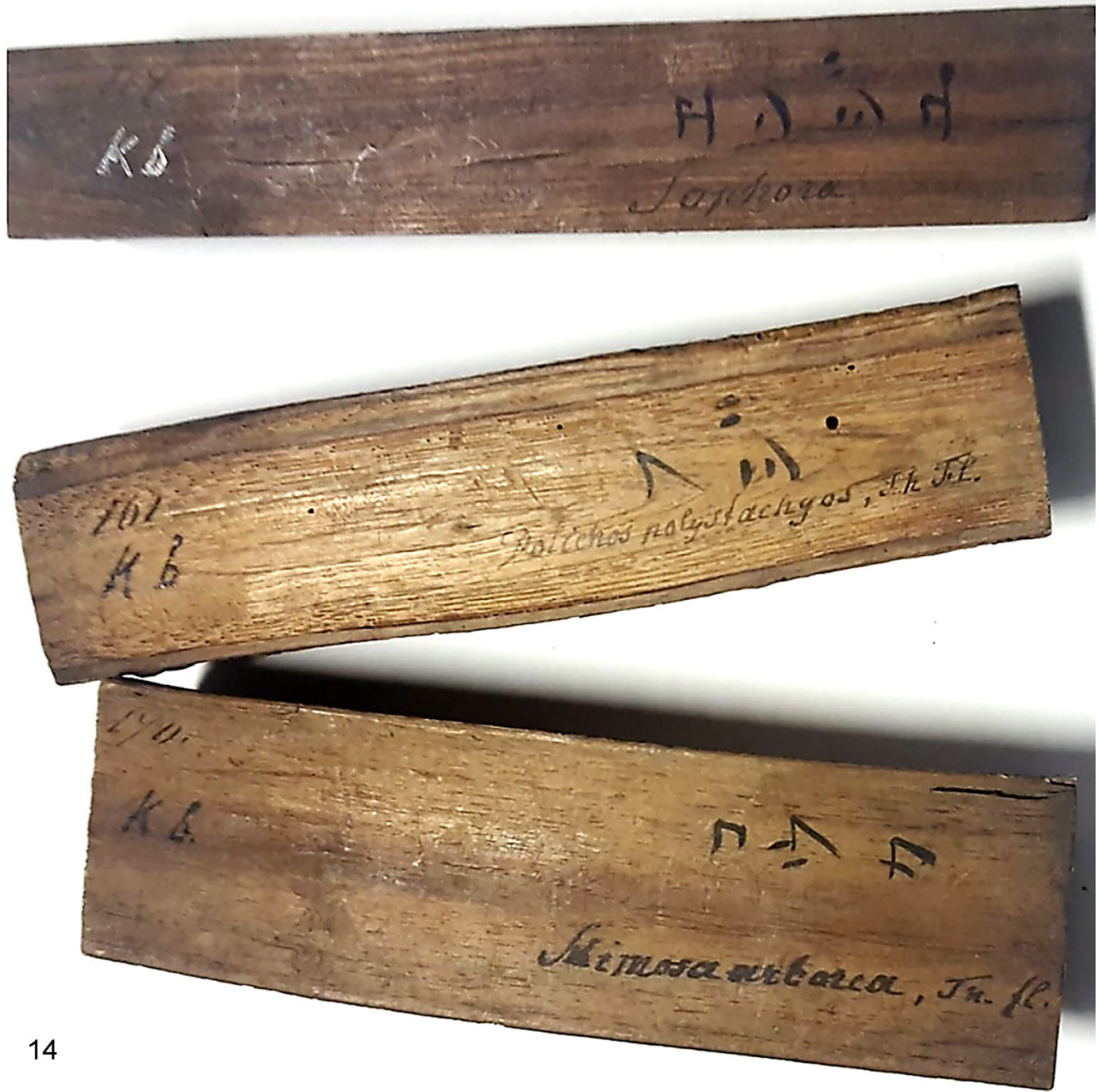

Figure 14. Three Japanese wood samples of the 225 specimens sent by Siebold to the Netherlands.

of Nördlinger. This speculation is supported by the finding of a personal handwritten letter by Nördlinger in one of Mechtild Mertz's copies of the Quick Guide (Mertz 2020, footnote on p. 80).

We do not (yet) know the precise links between the wood enthusiasts and forest botanists from the Siebold-Tokunai network of the early 19th century with the later flourishing of wood collections and wood research in Japan, which arguably reached its peak in the late 2oth century, but one can safely assume that Mogami Tokunai, the Siebold's (father and sons), and Ito Keisuke played significant roles that ultimately lead to Japan entering the world stage via the World Expositions of Vienna, Philadelphia, and Paris. World expositions were also to play a major role in the development of institutional wood collections associated with major museums and research institutions in Western countries in the 19th century, such as the xylarium of the Royal Botanic Gardens Kew in the UK (Cornish et al. 2013).

\section{EPILOGUE}

The 43-surviving hand-painted wood samples Mogami Tokunai donated to Siebold during the Court Journey of 1826 seem just a collection of anecdotal value, bearing some testimony to the wood culture of the now almost vanished Ainu people of Hokkaido. However, for Siebold they were considered of greater value, judging by his frequent references to wood uses noted on them in his later publications. With some imagination, we see a greater and lasting impact through the role Ito Keisuke played in 19th century Japan. This arguably greatest Japanese botanist of the 19th century (mainly remembered for his medical role in developing a vaccine against smallpox) arrived in 1827 in Nagasaki to study Western Science with Siebold and probably saw the charming Tokunai wood collection. Could the idea of decorating wood samples with botanical imagery have inspired the commissioning from Kato Chikusai of the xylothèque of hand-painted boards of over 15 o species at Tokyo University (Nagata et al. 2013)? Could Siebold's zeal in assembling wood samples and documentingowood culturezim Japan,:17:31AM 
have also stimulated the Expo-Museum co-ordinator and pupil of Ito Keisuke, Yoshio Tanaka, to submit the unusual collection of 100 species in the "Quick Guide" to the world expositions in 1876 (Philadelphia) and 1878 (Paris)? In that case, Siebold and Tokunai may have sown the seeds of the great surge in Japanese wood science in the 2oth century — but that is stretching our imagination to its farthest limits.

\section{ACKNOWLEDGEMENTS}

We thank Takao Itoh for information on traditional wood uses, and Elisabeth A. Wheeler and Emma E. van Nieuwkoop for help with the illustrations.

\section{REFERENCES}

Anonymous. 1873. Catalog der Kaiserlich Japanischen Ausstellung. Verlag Japanische Ausstellungs-Commission, 158 pp.

Anonymous. 1949. Important trees of Japan. General Headquarters, Supreme Commander of the Allied Powers. Report No. 119. Tokyo, 87 pp.

Anonymous. 1987. Report on forest resources. Effective utilization promotion project (in Japanese), Japan Housing and Wood Technology

Center, $392 \mathrm{pp}$.

Baas P. 1981. On some wood collections of historical interest. IAWA Bull. (n.s.) 2: $45^{-47}$.

Baba K. 2013. In memory of the late Professor Takao Yamaguchi. Cancer 22: 79-8o (in Japanese).

Bubner B. 20o8. The wood cross sections of Hermann Nördlinger (1818-1897). IAWA J. 29: 439-457. DOI: 10.1163/22941932-900oo197.

Compton JA, Thijsse G. 2013. The remarkable P.F.B. von Siebold, his life in Europe and Japan. Curtis's Botanical Magazine 30: $275^{-316 .}$

Cornish C, Gasson P, Nesbitt M. 2014. The wood collection (Xylarium) of the Royal Botanic Gardens, Kew. IAWA J. 35: 84-104.

Feuchter-Schawelka A, Freita W, Grosser D. 2001. Alte Holzsammlungen: die Ebersberger Holzbibliothek: Vorgänger, Vorbilder und Nachfolger. Geschichte und Gegenwart, Ebersberg.

Geerts AJC. 1883. Het tachtigste verjaardagsfeest van den Japansche Plantkundige Ito Keiske. Bijdragen tot de taal-, land- en volkenkunde $30(1): 341-35^{2}$.

Geerts AJC. $1875^{-76}$. Preliminary catalogue of the Japanese kinds of wood, with the names of the timber trees from which they are obtained. Transactions Asiatic Society Japan IV: 1-26.

Ishiyama Y. 1988. History of Rijksherbarium in Leiden and the botanical collections of von Siebold in relation with the open letter sent from Würzburg in 1864. In: Yanai K (ed.), The closed Japan and international cultural exchange II: 254-282. Yoshikawa-Kôbunkan, Tokyo (in Japanese).

Kanayama Y. 1999. A study of the museum idea before modern times and history of a modern museum establishment, part I. Bulletin of Museology, Kokugakuin University No. 24: 1-50 (in Japanese).

Körner H. 1967. Die Würzburger Siebold — Eine Gelehrtenfamilie des 18. und 19. Jahrhunderts. JA Barth Verlag, Leipzig, 662 pp.

Kouwenhoven A, Forrer M. 20oo. Siebold and Japan. His life and work. Hotei Publishing, 111 pp.

Mertz M. 2016. Wood and traditional woodworking in Japan. Kaiseisha Press, 227 pp.

Mertz M. 2020. Japanese wood and carpentry — rustic and refined. Kaiseisha Press, 130 pp.

Miquel FAG. 1870. Catalogues Musei Botanici Lugduno-Batavi Pars Prima, Flora Japonica. Martinus Nijhoff, The Hague, iii + 229 pp.

Nagata T, DuVal A, Lack HW, Loudon G, Nesbitt M, Schmull M, Crane PR. 2013. An unusual Xylothèque with plant illustrations from early Meji Japan. Economic Botany 67(2): 87-97. DOI: 10.1007/s12231-013-9227-6.

Nakamura Y. 1882. Ueber den Anatomischen Bau des Holzes der wichtigsten Japanischen Coniferen. Thesis, Munich.

Nördlinger H. 1852-1888. Querschnitte von hundert Holzarten, Volume I to XI. Cotta, Stuttgart.

Omori M. 1982. On some problems in the study of von Siebold performed until recently, and new materials relating to him and those concerned with him. Siebold Kenkyû, Bulletin of the von Siebold Society of Hôsei University No 1: 1-31 (in Japanese).

Posthumus L. 1874. Anatomisch onderzoek van Japansche Houtsoorten. PhD Thesis, Leiden.

Shimaya R. 1977. Mogami Tokunai. Yosikawa-Kôbunkan, Tokyo, 309 pp (in Japanese).

Sudo S. 2007. Wood anatomy in Japan since its early beginnings. IAWA J. 28: 259-284. DOI: 10.1163/22941932-900o1639.

Tanaka Y, Hirayana N. 1897. Participation notes for the Austrian World Exhibition (in Japanese).

Tanisawa S. 1983. The names of the wood samples given to Ph. Fr. Von Siebold by Mogami Tokunai: mainly on the relation of "Moshiho Guza" and "Ezogashima Kotoba". Siebold Kenkyû, Bulletin of the Siebold Society of Hôsei University No. 2: 1-42 (in Japanese with English summary).

Thijsse G. 2005. The history of the Herbarium Japonicum Generale in Leiden. In: Ohba H, Boufford DE (eds.), The botanical collections. Proceedings of the symposium "Siebold in the 21st century". University Museum, University of Tokyo Bulletin 41: 1-18.

Tsukahara T, Osawa M. 1989. On the Siebold collection of crude drugs and related materials. Bull. Tokyo Gagukei University. Sect. IV. Mathematics and Natural Sciences 41: 86-91.

van Oijen MJP, van Oijen JMJ. 2005. Von Siebold's reis naar het hof van de Shogun in het jaar 1826. Hotei Publishing, Amsterdam, 254 pp.

von Siebold PF. 183o. Synopsis Plantarum Oeconomicarum universi regni Japonici. Verhandelingen Bataviaasch Genootschap Kunsten en Wetenschappen 12: i-iv, 1-74, with 2 tables.

von Siebold PF. 1832. Verhandeling over de afkomst der Japanners. Verhandelingen van het Bataviaasch Genootschap der Kunsten en Wetenschappen 3: $184-276$.

von Siebold PF. 1858. Nippon, Archiv zur Beschreibung von Japan und dessen Neben- und Schützländern: Jezo met den südlichen Kurilen, Krafto, Kooräi und den Liukiu-Inseln, nach japanischen und europäischen Schriften undheigene Beobachtungen bearbeitet.1keidem.AM 
von Siebold PF. 1863. Handleiding bij het bezichtigen der verzameling van voorwerpen van Wetenschap, Kunst en Nijverheid en voortbrengselen van het rijk Japan. Bijeengebracht gedurende de jaren 1859 tot 1862 door Jhr. Ph.F. von Siebold. Amsterdam Vereeniging voor Volksvlijt (in Dutch).

von Siebold PF, Zuccarini JG. 1835-1870. Flora Japonica, sive, Plantae in Imperio Japonica collegit, descripsit, ex parte in ipsi locis pingendas. Lugduni Batavorum, apud auctorum. Two Volumes, $284 \mathrm{pp}+15$ o plates.

Wheeler EA, Gasson PE, Baas P. 202O. Using the InsideWood web site: potentials and pitfalls. IAWA J. 2020: 412-462. DOI: 10.1163.22941932bja1ooz2.

Yamaguchi T. 1997. Von Siebold and Japanese Botany. Calanus Special Number I. Bulletin Aitsu Biological Station, Kumamoto University, pp. $1-238$.

Yamaguchi T, Kato N. 1998. Mogami Tokunai's collection of wood specimens donated to von Siebold and now housed in the Rijksherbarium, Leiden. Calanus Special Number II. Bulletin Aitsu Biological Station, Kumamoto University, pp. 447-496.

\section{Edited by Keiko Kuroda}

\section{APPENDIX}

Table A1.

Texts on the wood specimens in Japanese characters by Tokunai. In the following sequence: Japanese names in katanaka, hiragana and/or kanji characters; Ainu name on sample (and in parentheses as spelled on Ainu Museum website, http://www.ainumuseum.or.jp/siror/dictionary/); uses in kanji and katanaka characters written by Tokunai for only few of the wood samples.
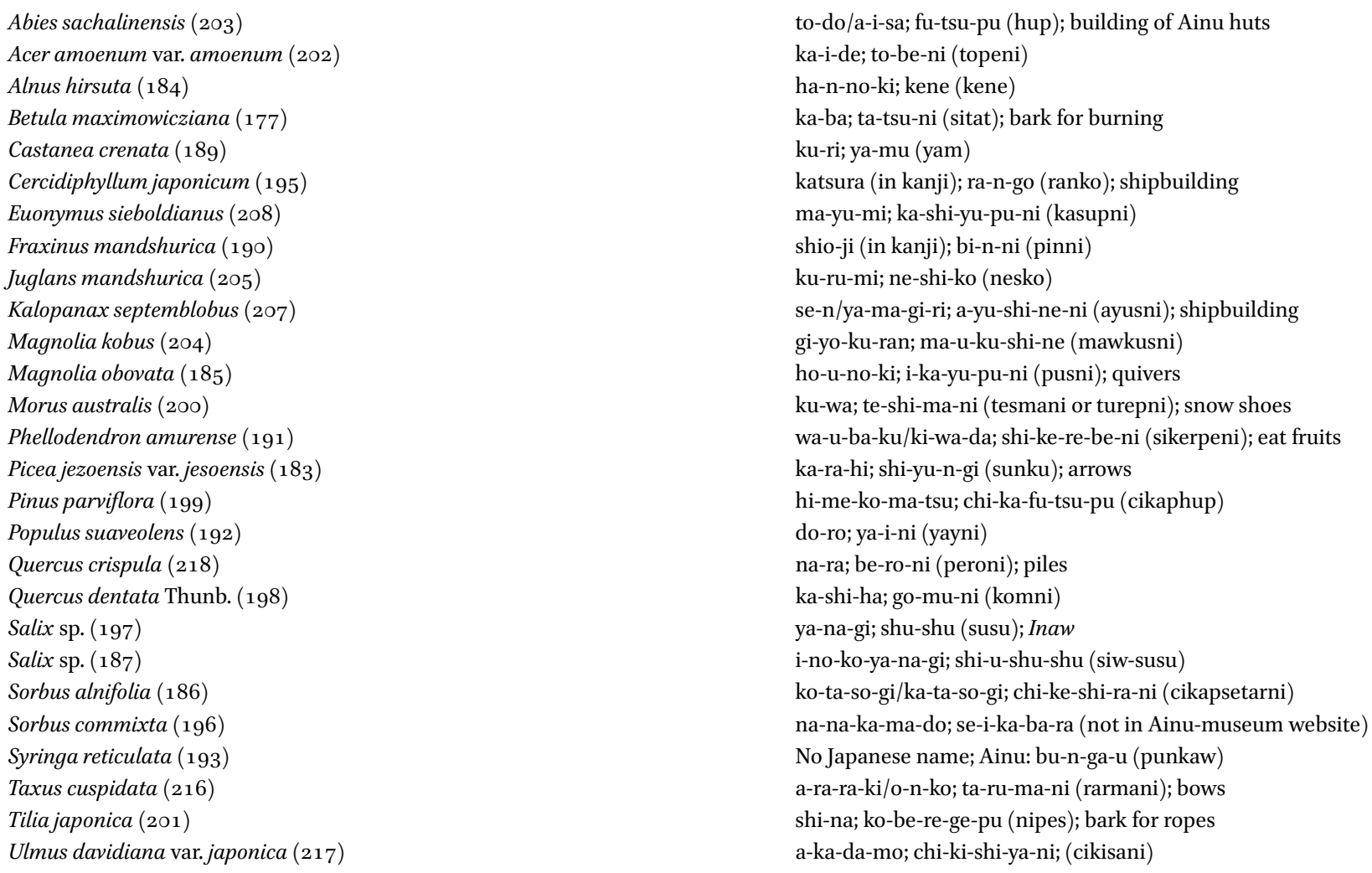